\title{
Study on the Demands for Agricultural and Rural Informationization in China and Its Strategic Options
}

\author{
Jin $\mathrm{Li}^{1}$, Chunjiang Zhao ${ }^{1, *}$, Xiangyang $\mathrm{Qin}^{1}$, and Gang $\mathrm{Liu}^{2}$ \\ ${ }^{1}$ National Engineering Research Center of Information Technology in Agriculture, \\ Beijing, P.R. China \\ Tel.:+86-10-51503595; Fax: +86-10-51503750 \\ zhaocj@nercita.org.cn \\ ${ }^{2}$ College of Information \& Electronic Engineering, China Agricultural University, \\ Beijing, P.R. China
}

\begin{abstract}
China is at a critical stage of transformation from traditional to modern agriculture and its agriculture and rural economic sector faces severe challenges of shortage of natural resources, environmental degradation, agricultural disasters, sluggish income growth of farmers and widening disparity between urban and rural areas. The fundamental solution to these problems lies with the advancement of agricultural science and technology. China's agricultural and rural informationization has entered the comprehensive development stage, in which informationization is no longer a pure technical but complex systematic matter, involving natural, technological, economic and social issues, with impact on the country's food security, environmental protection and sustainable development. Based on analysis of agricultural and rural economic development, this paper thoroughly examines the demand for information technology in the drive of new socialist countryside construction and modern agriculture development and tables strategic options for agricultural and rural informationization in China.
\end{abstract}

Keywords: modern agriculture, new socialist countryside, informationization, needs analysis, strategic options.

\section{Introduction}

At late 90's of the last century, China's agricultural development entered a new stage; the supply of agricultural products has changed from shortage to an overall equilibrium of supply and demand while surplus has been maintained in years of good harvest; the structure of agricultural production has been gradually optimized; transition from traditional agriculture featuring monopoly crop farming to modern agriculture with overall development of agriculture, forestry, animal husbandry and fisheries has been achieved. Agricultural production has become increasingly commercialized, specialized and market oriented. In the national economy, it has transited from agriculture supporting industry to industry supporting agriculture and urban area leading the

* Corresponding author.

D. Li, Y. Liu, and Y. Chen (Eds.): CCTA 2010, Part III, IFIP AICT 346, pp. 580-591, 2011.

(C) IFIP International Federation for Information Processing 2011 
development of rural area. The development and innovation of rural economy of China have not only done away with the backwardness of rural China, but also provided strong support to industrialization and modernization of the country.

\subsection{Significantly Improved Agricultural Comprehensive Production Capacity and Transition from Traditional to Modern Agriculture}

Since reform and opening, agricultural infrastructure facilities nationwide have been significantly improved. Farmland irrigation, agricultural mechanization and facility agriculture developed rapidly; the equipment level, disaster resistant capacity and resource utilization efficiency also improved remarkably. As a result, agricultural comprehensive production capacity has greatly improved. In 2008, the total power of agricultural machineries reached 822 million KW and the mechanization level of farmland plowing and crop planting and harvesting reached $50.8 \%$. The gross output value of agriculture reached 5.83 trillion RMB Yuan, the added value of primary industry reached 3.4 trillion RMB Yuan. Total grain output attained 528.5 million tons and the per capita grain output reached $400 \mathrm{~kg}$, providing strong foundation for national food security. The development objective of agriculture is changing from "providing sufficient food and clothing" to "high quality, high yield, high efficiency, ecological-friendliness and safety". The industrial system of agricultural sector is shifting to the establishment of modern agricultural industrial chain. Different operational models of agricultural development such as those led by dragonhead enterprises through "company + farmer households", by intermediary organizations through "cooperative + farmer households" and "specialized association + farmers households" and led by specialized markets have flourished. The process of market-oriented commercialization and specialization of agricultural production has accelerated, laying solid foundation for modern agricultural development.

\subsection{Continuous Optimization of Agricultural and Rural Economy Structure and Gradual Improvement in Quality and Result}

At present, the structure of agriculture, forestry, animal husbandry and fisheries has achieved transition from traditional agriculture featuring monopoly crop farming to modern agriculture of integrated development of agriculture, forestry, animal husbandry and fisheries. The share of crop farming decreased while the shares of forestry, animal husbandry and fishery increased significantly in the total output value of agriculture, forestry, animal husbandry and fisheries. In 2008, the gross output value of agriculture reached 3.4 trillion RMB Yuan, an increase of 5.5\% on the basis of last year in comparable terms. Crop farming accounted for $53.3 \%$ of the total output value, forestry for $4.4 \%$, animal husbandry for $29.4 \%$ and fisheries for $9.4 \%$.

In the sub-sector of crop farming, the ratio of sown areas to grain, cash and other corps has changed from $89.2: 9.0: 1.8$ in 1952 to $68.3: 27.8: 3.9$ in 2008, with significantly increased proportion of cash crops. In the structure of animal production, the output of pork declined from $94.2 \%$ in 1952 to $63.5 \% \%$ in 2008 , while beef and mutton increased from $5.74 \%$ in 1979 to $13.6 \%$ in 2008 . Poultry meat also rose from $5.80 \%$ in 1985 to $22.9 \%$ in 2008 . Egg and milk production has witnessed rapid increase and their share in animal products also went up by a big margin. 


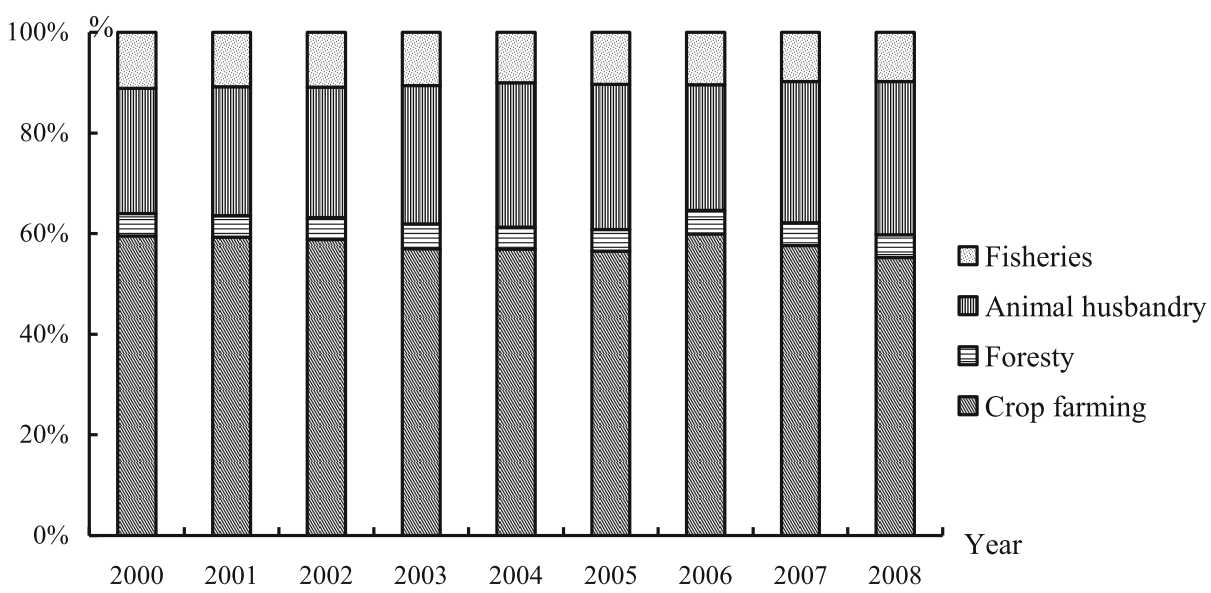

Fig. 1. Composition of value added by agriculture, forestry, animal husbandry and fisheries 2000 to 2008

Data resources: Analysis and Forecast of China's Rural Economic Situation (2008-2009), Rural Development Research Institute of Chinese Academy of Social Sciences and Rural Social and Economic Department of National Statistics Bureau of China: Social Science Literature Publishing House, 2009.

At the same time, rural economic structure has also changed from being dominated by agriculture to coordinated development of the three industries. According to statistic data of the Second National Agricultural Census, China had a total number of 239,000 agricultural enterprises engaged in various industries of agriculture, forestry, animal husbandry and fisheries at the end of 2006. In 2008, the added value of primary industry accounted for $29.1 \%$ of the total added value, a drop of $19.4 \%$ on the basis of 1997 . Correspondingly, the added value of secondary and tertiary industry was $54.6 \%$ and $16.3 \%$ respectively, representing an increase of $10.1 \%$ and $9.3 \%$ on the basis of 1997 . In the past two years, due to the impact of global economic slowdown, demand decline and changes in domestic economic environment, the development of township enterprises slowed down significantly and secondary and tertiary industries experienced the same pattern of decline. However, the overall trend of coordinated development of the three industries will not change.

Data resources: Analysis and Forecast of China's Rural Economic Situation (2008-2009), Rural Development Research Institute of Chinese Academy of Social Sciences and Rural Social and Economic Department of National Statistics Bureau of China: Social Science Literature Publishing House, 2009.

\subsection{Significantly Improved Farmers' Livelihood and Great Success in New Countryside Construction}

The 17th National Congress of the Chinese Communist Party proposed for the first time the "acceleration of social development focusing on improving people's livelihood". From 2003 to 2008, the total expenditure in "agriculture, rural areas and farmers" from the central government finance reached 2.2 trillion RMB Yuan, which 


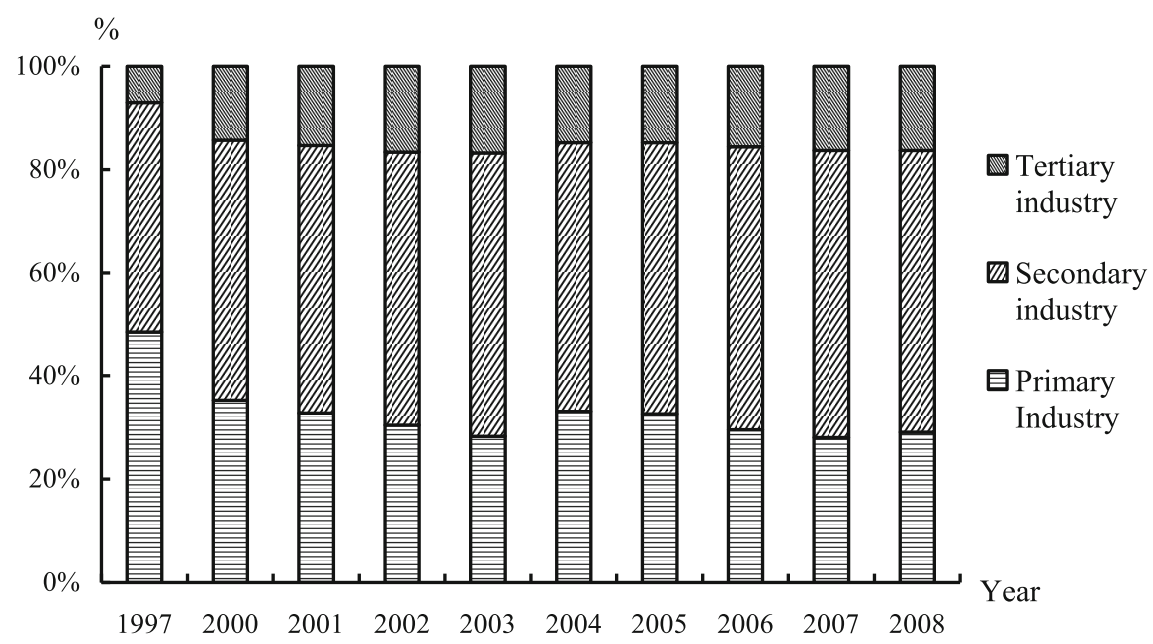

Fig. 2. Composition of value added by sectors of rural areas from 1997 to 2008

resulted in significant improvement of the livelihood in rural areas. Rural power grid transformation program has provided electricity to more than 5.3 million households of about 24 million people who had no access to power otherwise; rural safe drinking-water program benefited 130 million rural residents. The proportion of administrative villages in the country with access to road, telephone, electricity and television signal accounts for more than $95 \%$ of the total and more than $80 \%$ townships have postal services. Education, sanitation and medical service in rural areas have improved substantially; farmers' income and consumption have both increased. In 2008, the per capita net income of rural residents reached 4,761 RMB Yuan, which was 34.6 times higher than that in 1978, presenting an average annual growth rate of $12.7 \%$ and $7.1 \%$ after deducting price factors. The number of farmer households with per capita net income over 5,000 RMB Yuan accounted for 39.3\% of the total farmer households, of which $9.3 \%$ garnered more than 10,000 RMB Yuan in per capita net income. A historic leap from subsistence to moderate prosperity has been achieved in the livelihood of rural residents and it is advancing towards the goal of well-off society in all-round manner.

Even though farmers' income has been increasing rapidly, the urban-rural gap is also widening, which has expanded from 2.6:1 in 1978 to 3.3:1 in 2008 (with the income of rural resident as 1); the gap in absolute amount expanded to 11,020 RMB Yuan. Because of the dual-tier economic and social structure established long time ago, the urban-rural gap will remain for certain period of time.

\subsection{Increased Impact of Agriculture and Rural Economic Development on the Growth of National Economy}

At present, China is at the middle stage of industrialization. In 2008, the per capita GDP exceeded 3,000 USD, while the ratio of output value of primary industry in GDP dropped to $11.3 \%$ and the employment size of primary industry made up only $39.6 \%$ of the entire 
society; urbanization rate reached $45.68 \%$; indicating that industrialization and urbanization of China have already entered a new stage. The complementarities and interactions in development between rural and urban areas have been enhanced. Agriculture and rural economy is increasingly integrated with industrial and urban economy. The impact of agriculture and rural economy on the national economy has increased significantly. Particularly, during current international financial crisis, China's central government staged up investment in rural areas and stimulated rural residents' consumption, which is an important way of expanding domestic demand. Through implementation of programs such as getting household electric appliances, motorcycles, building materials and vehicles to rural areas, the government aims at achieving new momentum of economic growth pulled by increased consumption in rural areas, which provided important foundation to achieving the objective of "maintaining growth".

\subsection{Severe Challenges in the Development of Agriculture and Rural Economy}

The 5th Plenary Session of the 16th Central Committee of the Chinese Communist Party proposed the mission of building new socialist countryside. The key of building socialist new countryside is to promote the development of modern agriculture. For the time being, China is at the critical stage of transiting from traditional to modern agriculture and its agriculture and rural economic development faces severe challenges of natural resource shortage, ecological environment degradation, frequent agricultural disasters, low labor productivity, sluggish income growth of farmers and widening urban-rural gap.

In China, the situations of water resource shortage and low-efficiency use exist at the same time. At present, water use for agricultural irrigation accounts for $70 \%$ of total water use of the entire society. Due to problems in water transportation, irrigation, on-farm irrigation infrastructure facilities, farming system and farming practices, agricultural water use efficiency in China is still low, the grain production efficiency of unit net water consumption is less than $1 \mathrm{~kg} / \mathrm{m} 3$, which is far behind $2-3 \mathrm{~kg} / \mathrm{m} 3$ in developed countries. Agricultural irrigation water use in the Yellow River basin accounts for $92 \%$ of the total water consumption, but almost $80 \%$ of the farmland is irrigated through gravity flooding and only $20 \%$ or about 22.76 million mu is irrigated through water-saving techniques.

The deterioration of arable land quality and the degradation of soil environment have become the bottleneck to the development of agricultural production, which is also a technical problem that must be addressed for sustainable agricultural development. According to statistics, the total arable land area in China is 1.827 billion mu, $1.39 \mathrm{mu}$ per person, which is less than $40 \%$ of the world average. Desertification area in the country is about 2.63 million $\mathrm{km} 2$, accounting for $1 / 3$ of the total land territory; sandification area is 1.73 million $\mathrm{km} 2$, accounting for $1 / 5$ of the total land territory. The declining trend of arable land quality is also obvious, which is mainly reflected in shortage of organic matter in soil. When examining the organic matter content of arable land of China, it is about $1-3 \%$ for most of paddy soils; upland with less than $1 \%$ of organic matter content accounts for $31.2 \%$ of the total upland cropland.

The agricultural productivity and labor production rate are not high. Farming in most parts of the country is still done by hands and draft animals. Mechanized plowing accounts for only $55 \%$ of the total arable land area, mechanized sowing for $24.9 \%$ and 
mechanized harvesting for $10 \%$. Low level of mechanization and artificial intelligent control in agricultural production directly resulted in low return rate of agricultural labor and small margin of farmers' income growth.

\section{Demand for Information Technology Triggered by Substantive Changes in Agricultural Production Patter in China}

\subsection{Scale Production of Agriculture Needs Automated and Intelligent Machinery and Equipment}

Scale operation, intensification and informationization are not only the features of modern agricultural production, but also important ways for transiting from traditional to modern agriculture. Currently, China has built up an agricultural mechanization development system in consistent with China's national condition. The level of agricultural equipment and mechanization achieved leap development. In 2008, the comprehensive mechanization level of farmland plowing, crop planting and harvesting reached $50.8 \%$. Field machineries with high performance and power and the corresponding farm implements increased rapidly; therefore, agricultural mechanization has entered the intermediate stage of development. Along with the development of science and technology in the globe as well as the development of computer technology, remote sensing and detecting technology, information processing technologies, controlling technology and global positioning technology, the performance of agricultural machineries has been greatly improved. In case of harvester for example, with the application of grain flow-sensing unit, the quality of grain harvested per second can be rapidly detected. With the use of grain moisture sensor, the humidity of the grain harvested and stored can be measured and monitored on-line. Agricultural robot that depends on artificial intelligence technique to sense crop species and environment change can work under extremely hot, humid or noxious environment and easily accomplish production-related works such as picking, sorting and application of pesticides. The utilization of those advanced techniques has greatly increased the efficiency and safety of farm operations[1]. At present, the first GPS-based intelligent variable seeding, fertilizer application and rotary plowing machine with independent intellectual property rights has been successfully developed and used in Maoxin Farm of Songjiang of Shanghai. The first domestically made GPS harvester has been released by Foton Heavy Industries. The application of new and high technologies represented by information technology is the key for modern agriculture to become a technology-intensive industry of scales [2].

\subsection{Industrialization of Agriculture Needs High Efficiency and Convenient Channel of Information Communication}

Agricultural industrialization is a complete industrial chain that links the various stages of pre-production, production and post-production. Informationization is the fundamental requirement of industrialization and the important means of industrial development. It provides not only sufficient information resource and convenient communication channel, but also effective technical means for industry integration and management enhancement in agricultural production [3]. Through computer management and decision-making support 
system, it can help simulate and make decisions in the process of industrialization and lower the cost and risk. Through networking, market and policy information can be timely obtained, hence products can be identified for production and marketing in line with market demand. Agricultural product tracking system can track and identify products, which can safeguard quality and safety of farm produces. Informationization has significantly changed the traditional production and marketing approaches and provided greater opportunities for further development of the traditional industry.

\subsection{Precision Management of Agriculture Needs Digital and Precise Agricultural Information Resources}

Precision management refers to the use of programmed, standardized, digitalized and informationized means to achieve precise, efficient, coordinated and sustained operation of each organization and management unit. Since agricultural resources are dispersed, changeable and uncertain, over $85 \%$ of agricultural information resources are related to spatial position. Therefore, the application of $3 \mathrm{~S}$ technique, database technique, MIS technique, networking technique and decision-making support technique in the management of agricultural resources to dynamically monitor agricultural resources can efficiently promote optimized resource allocation and improve resource utilization efficiency[4]. Let's take agricultural resource management and decision-making support system as an example. Based on agricultural resource database, the system through integrating professional models and expert systems can implement various analysis and decision-making as rational utilization of water, cropping structure adjustment and fertilizer application tactics[5]. Digitalization and informationization are important features and means in the transition from extensive to intensive agriculture.

\section{Social Development in Rural Areas Needs Information Technology}

\subsection{Orderly Transfer of Rural Labor for Employment Needs Communication Platform of Demand and Supply of Labor}

Along with ever sharpening contradiction of less land and large population in rural areas and protracted urbanization, more and more rural surplus labors are moving to urban areas. At present, rural surplus labor accounts for $1 / 3$ of the total rural labor force of the country and less than $1 / 2$ of the surplus labors can be effectively transferred to urban areas. In order to prompt the orderly transfer of rural labors and optimize the deployment of labor resources, it is essential to build and improve rural service platform for labor supply and demand to realize dynamic management of basic information of labors and employers, such as timely releasing, inquiring and communicating of employment information. Meanwhile, the development of Internet technology enables farmers to expand their information capture and provides farmers with opportunities to access employment information of urban areas, which can help expand channels of employment. 


\subsection{Serving the Improvement of People's Livelihood Needs Information Technology to Speed Up Social Development of Rural Areas}

The fact that information can benefit people's livelihood and network can help build harmony has become a consensus of the globe. Through informationization, farmers can better access essential information and services needed in daily life, such as those related to culture, education, medical care and social security. The programs of "broadcasting outreaching villages" and "live satellite coverage outreaching villages" implemented by the State Administration of Radio, Film and Television have greatly improved the coverage of broadcasting and television and enriched the spiritual and cultural life of farmers. In the field of medical care, disease monitoring information system is beginning to demonstrate its usefulness. The application of rural cooperative medical care management information system is catching more and more attention and gaining stronger development. Explorations and trials of modern distance medical service have been carried out in some areas. The service facilities as "Digital Homeland", "Agricultural Information Courier Station" and "Agricultural Information Service Station" of Beijing have delivered information to the doorsteps of farmers, providing convenience to the life of farmers[6]. The establishment and improvement of socialized service information system in rural area is an important means to achieve coordinated urban-rural development and reduce urban-rural gap.

\subsection{Standardization and Enhancement of Rural Management and Service Need the Support of E-government Platform}

According to the survey of UNESCO, $89 \%$ of countries are about to promote e-government and have set it as an important national agenda. At present, the large amount of governance affairs in rural areas compounded by poor management means and obscurity in information disclosure is the important cause of instability of farmer-cadre relationship. Through the establishment of administrative management system in rural area, government functions can be transformed and village management can be improved[7]. The daily work of grassroots government can be achieved via Internet and this paperless work style can greatly reduce procedures and enhance the efficiency of work. The development of e-government increases farmer's political participation, safeguards their rights to be informed of village affairs and improves their sense of being masters of their own and ultimately promotes institutionalized and standardized administration of rural areas.

\section{Agricultural and Rural Informationization Is an Important Means of Achieving Leap Development in Productivity}

\subsection{Informationization Promotes the Shift from Extensive to Intensive Economic Growth}

The mechanism of turning information technology into economic growth is that, with the innovation of information technology, the cost of manufacturing and prices of information products and equipment fall rapidly, which stimulates investments in information technology by various economic sectors, forming the so-called IT capital 
deepening. It not only improves the productivity of the sector, but also gains spillover effect onto other sectors in terms of behavior and productivity, hence it promotes technology progress and organizational change of economic sectors, thereby fosters the transition of the entire economic growth pattern.

As an intrinsic element of the productivity system, agricultural information plays certain role in agricultural economic growth through labor tools, labor and object of labor, such as various intelligent agricultural machineries and implements, agricultural production decision-making support system, expert system and monitoring and control system [8]. With extensive application of information technology, large-scale innovation has appeared in agriculture and rural industry, significantly improving technical performance of tools, upgrading technical qualification and operational skills of labors, optimizing the objects of labor and saving resources. Therefore, agricultural production has changed from mainly relying on increased input to improving the production efficiency of elements to achieve output increase, which has promoted the change from extensive economic growth pattern driven by quantity to intensive pattern driven by quality.

\subsection{Informationization Reduces Energy and Material Consumption in Agricultural Production and Alleviates Pressure of Economic Development on Population, Resources and the Environment}

Traditional industrialization and economic growth pattern of "high investment, high consumption, high pollution, low output, low quality and low efficiency" has caused global resource shortage, environment pollution and ecological deterioration. Statistic data of the Ministry of Agriculture shows that the annual chemical fertilizer application in China is 47 million ton, while the effective utilization rate is only $35 \%$; the annual pesticide use is more than 1.4 million ton while the effective utilization rate is about $30 \%$, irrigating water utilization efficiency is only $45 \%$. Large amount of livestock manure is not fully used as resources and its contribution of methane to greenhouse gases is 21 times of $\mathrm{CO} 2$. Energy conservation and emission reduction in agriculture not only plays decisive role in achieving the national goal of energy conservation and emission reduction, but also bears great significance in developing modern agriculture and safeguarding food security of the country.

Technically, informationization provides the possibility for the emergence of modern productivity of low resource consumption [9]. Through integrating remote sensing GIS, GPS, communication and network technologies and automated technologies with geography, agronomy, ecology and soil science, precision agriculture has achieved real-time monitoring of crop and soil in macro and micro dimensions during the whole production process. Thus, rational utilization of agricultural resources, improvement of ecological environment, reduction of resource and energy consumption and increase the quality of agricultural product can be materialized [10].

\subsection{Informationization Brings about Incremental Benefits of Agricultural Structure Adjustment}

Industrialization is an important way of promoting agricultural structure adjustment and an effective measure of increasing farmers' income. However, at present stage, because of small-scale operation and geographic dispersion, the circulation of 
agricultural products is slow and the overall integration of agriculture is not high either. Market is the center of information, from the perspective of market system, agricultural operation mainly relies on timely and accurate market information to deploy agricultural and rural industrial resources to achieve the goal of optimization and operation of high efficiency.

On the other hand, with gradual improvement of agricultural informationization, information industry in rural area will become an emerging service industry. In the future, profit oriented exchange of agricultural information service and agricultural information products in rural market system will become important elements. With the development of rural information industry, more and more people will engage in information service, including collection and processing of information, software development, marketing of information products and consultation.

\section{Conclusion}

This paper has demonstrated the demand for information technology in the drive of new socialist countryside construction and modern agriculture development. To guarantee the effect of agricultural and rural informationization, we proposed several strategic options as follows.

\subsection{Institutional Innovation: Organizational Guarantee of Informationization}

Promoting the application of information technology in agriculture and rural area is the foothold of informationization; it is also the inevitable way of developing modern agriculture and constructing new socialist countryside. As the user of informationization, farmers are not highly enthusiastic about the use of information technologies due to constraints of knowledge and concepts and the impact of low income and high cost of accessing information and information technologies, which severely hinders the process of agricultural and rural informationization. In order to resolve the problem, it is a must to innovate the mechanism of informationization. Firstly, there is the need to innovate a subsidy system of agricultural information. Through subsidizing modern technologies (equipment) and lowering the economic access requirements to modern information technology, it is to support large farmer households, intermediary agents and farmer cooperative organizations to actively use modern information technologies. The demonstration and leading role of these actors should be fully tapped to promote agricultural industrialization through informationization. Secondly, there is the need to innovate diversified investment system. The guiding role of government's agriculture-supporting and benefiting funds should be fully used to usher credit and capital investment of the society in agriculture and rural information development, building a financing system integrating government's input, capital investment of the society and farmer's contribution. An effective organization and coordination mechanism should be established among agricultural and agro-sectors. Close cooperation mechanism should be established among the telecommunication operators, IT enterprises, civil organizations and farmers [11]. 


\subsection{Science and Technology Innovation: The Driving Force of Informationization}

Science and technology is first productivity. Agricultural science and technology innovation is extremely important to a developing country like China that is short of agriculture resources. In the research field of rural informationization, efforts should focus on the demonstration, application and large-scale use of mature technologies, such as "the integration of the three networks" in rural areas, mobile broadband connectivity and its service, LAN data exchange technology based on power distribution network, sharing of rural information resources, network information discovering and intelligent analysis technology, cloud calculation platform and cloud service model and public information and management service platforms in rural areas. In rural informationization research area, priority should be given to monitoring and management of water and soil resources, early warning of epidemic diseases of intensive livestock farming environment, long distance monitoring of biological environment of facility horticulture industry, monitoring of agricultural production environment and transportation process, long-distance dispatch and diagnosis service of large agricultural machineries [8].

\subsection{Capacity Building: Human Capacity Support to Informationization}

Along with the advancement of economic globalization, the competition for talents becomes increasingly fierce. The upgrade of national comprehensive strength increasingly relies on science and technology progress and the fostering of talents. Since the 1990 's of the 20th century and with the continuous innovation of information technology, informationization has become an important stage of modern agricultural development and new countryside construction. And the key to realize informationization lies with the setting up of human resource structure that meets the needs of agricultural and rural informationization and provides human resources to rural informationization. Therefore, efforts must be made to build up human resource capacity for rural informationization. On one hand, based on innovations, with independent intellectual property rights, of domestic first class universities and colleges as well as research bases, it is to realize innovation from the source of core technique to product equipment and foster innovation-oriented talents. On the other hand, high-level information-oriented personnel with good command of modern information technologies and agricultural production operations in the grassroots of rural areas should be fostered, so as to realize popularized application of new technologies and products in grassroots.

\subsection{International Cooperation: An Accelerator of Informationization}

Along with accelerated development of science and technology, global and regional cooperation is unfolding. No country in the world can resolve all development problems on its own and international cooperation has become an important way of addressing developmental issues. Through international cooperation, strategic cooperation with information and technology enterprises of developed countries should be strengthened to introduce into the country more advanced technologies to promote leap development and re-innovation. Priority should be given to research subjects that can help attract international cooperation funds or foreign advanced technology, equipment 
and advanced method. Joint application with strong overseas establishments for R\&D of key technologies should be encouraged.

\section{Acknowledgements}

This study is funded by the National Social Science Fund (approval number: 10OCQ006) and National Natural Science Foundation of China (approval number: U0970173). The authors wish to thank Academician Maohua Wang, Professor Liping Chen, Professor Xinting Yang for their constructive comments and suggestions which increase the quality of the manuscript significantly.

\section{References}

1. Sun, J.: The General Theory about Agriculture Informationization. China Science and Technology Press, Beijing (2001)

2. Rural and Social Development Division, Ministry of Science and Technology. In: China Digital Agriculture and Rural Development Strategy Symposium. China Agriculture Press, Beijing (2003)

3. Guo, Z.: Introduction to China's Rural Market Information Service. China Agriculture Press, Beijing (2008)

4. Information and Electronic Engineering Faculty. In: Chinese Engineering Academy, Strategy on the Sustainable Development of Informationization in China. Science and Technology Press, Beijing (2007)

5. Zhao, C.: Research and Practice of Precision Agriculture. Science Press, Beijing (2009)

6. Li, D.: Rural Informationization Development Report in China. Electronic Industry Press, Beijing (2008)

7. Liu, S.: Agriculture Information Technology and Rural Informationization. China Agricultural Science and Technology Press, Beijing (2005)

8. Wang, M.: ICT for Agriculture and Practice of Precision Farming. In: International Symposium on Intelligent Information Technology in Agriculture International Conference Theme Report, Beijing (2005)

9. Wang, M.: The Necessity and Possibility to Extend ICT Application for Sustainable Agriculture in China. Invited speech by the Science Council of Japan, Tokyo (2007)

10. Zhao, C., Xue, X., Wang, X., et al.: Advance and prospect of precision agriculture technology system. Transactions of the CSAE 19, 7-12 (2003)

11. Ministry of Agriculture. National Agriculture and Rural Informationization Construction Framework (2007-2015), Beijing (2007) 